Article

\title{
Durability Characteristics of Concrete Mixture Based on Red Ceramic Waste Aggregate
}

\author{
Marie Horňáková ${ }^{1, *}$, Petr Lehner ${ }^{1}$, Tuan Duc Le ${ }^{1} \mathbb{D}$, Petr Konečný ${ }^{1} \mathbb{D}$ and Jacek Katzer ${ }^{2} \mathbb{D}$ \\ 1 Department of Structural Mechanics, Faculty of Civil Engineering, VSB-Technical University of Ostrava, \\ Ludvíka Podéště 1875/17, 70833 Ostrava-Poruba, Czech Republic; petr.lehner@vsb.cz (P.L.); \\ tuan.duc.le@vsb.cz (T.D.L.); petr.konecny@vsb.cz (P.K.) \\ 2 Faculty of Geoengineering, University of Warmia and Mazury in Olsztyn, 10-720 Olsztyn, Poland; \\ jacek.katzer@uwm.edu.pl \\ * Correspondence: marie.hornakova@vsb.cz
}

Received: 15 September 2020; Accepted: 22 October 2020; Published: 27 October 2020

\begin{abstract}
The article aims to observe durability parameters of red ceramic waste aggregate concrete based on a measured chloride profile by the standardized NT Build 443 method, and to compare the results to the values measured by a test based on electrical resistivity measurements. The parameters related to the chloride ion diffusion are investigated on the new type of concrete designed in the previous project, which contains waste material-red ceramics fine aggregate, and artificial expanded clay coarse aggregate. Ceramic materials contribute to the highest percentage of the construction and demolition wastes and, in most cases, this type of waste is disposed of in landfills. Significant factors limiting the use of the studied material are the unavailability of standards, avoidance of risk, and lack of knowledge and experience in using ceramic wastes for construction purposes. The obtained results of the studied mixture are compared to a reference concrete in terms of mechanical properties and durability parameters. The calculated diffusion coefficient is a crucial input parameter for modeling of the degradation process and the prediction of concrete durability; therefore, proper identification is of interest in order to allow for a broader application of ceramic waste aggregate-based concrete. The research showed unproportionality of results measured by the two methods in the case of waste aggregate concrete (60\% difference in comparison with reference concrete), therefore it was proved that the electrical resistivity measurements need correlation of the resulting diffusion coefficient for proper modeling.
\end{abstract}

Keywords: concrete; chloride profile; diffusion; durability; red ceramic waste aggregate; resistivity; sustainability

\section{Introduction}

The sustainability of every aspect of human life is a frequently discussed problem in the last few decades. In terms of civil engineering, one of many issues within this field is massive amounts of demolished concrete and brickwork, while the manufacturing of new concrete and bricks causes a reduction of natural resources [1,2]. Therefore, recycling and reusing waste or unsuitable building materials as a total or partial replacement of traditional concrete ingredients are of the highest interest. New concrete mixes present unique challenges, as standard procedures for measuring mechanical and durability parameters may not be appropriate and sufficient $[3,4]$. These properties are important not only in terms of classification among other concrete mixtures but also in terms of numerical analysis [5], which today offers enormous opportunities for improving the sustainability of a design because it is included in the preparation of structures and the analysis of existing structures. It is therefore desirable to evaluate the mechanical properties at the beginning of each analysis. They are necessary 
also in terms of durability analysis and time-dependent behavior with respect to ultimate limit state performance [6], as has been proven, e.g., in [7], where a reinforced concrete bridge deck was evaluated by multilevel durability analysis. Compressive strength of concrete is directly linked to its quality and sustainability [8].

The aim of the article is to compare the quality characteristics, such as mechanical properties and durability parameters related to chloride diffusion of structural lightweight waste aggregate concrete (SLWAC), and compare them to a reference concrete mixture. The mechanical properties of the mixture have been presented previously in [9], and for the evaluation of the quality of concrete mixture the durability properties in selected exposure conditions are needed as well. The following durability tests were conducted, namely, resistivity tests and accelerated chloride penetration by NT Build 443 .

The electrical resistivity of concrete is an important indicator of concrete's quality, as shown in various studies $[10,11]$. It was proved that concretes with higher values of surface electrical resistivity are characterized by lower permeability and porosity. Thus, the corrosion probability of reinforcement is reduced. An indisputable advantage of the resistivity test is its non-destructiveness and, therefore, it is possible to obtain a time-dependent diffusion characteristic of concrete. The relation between compressive strength and electrical responses of concrete is a subject of many kinds of research, e.g., [3,12-14]. Moreover, the durability-related parameters and their correlation have been of interest among researcher for more than a decade $[12,13]$. One of the key factors for determining the compressive strength is the strength of the interfacial transition zone, which does not majorly influence concrete's electrical resistivity. Some research [14] has observed that the relationship between compressive strength and electrical resistivity of concrete is not influenced by the chemical compounds of different cementitious materials. The chemical compounds significantly affect concrete's resistivity, but do not have such an impact on the strength properties. The correlation between compressive strength and concrete resistivity can be more substantial for similar cementitious materials due to the relationship between permeability and compressive strength. It is worth mentioning that the electrical resistivity and compressive strength increase as concrete permeability decreases. However, some authors consider the electrical resistivity measurements and composition of concrete as independent characteristics [15]. The relationship between compressive strength and resistivity can be affected also by other properties during the maturing of concrete, such as the conductivity of the pore solution and the degree of saturation [16].

The immersion test NT Build 443 [17] is a Nordic method based on APM 302 [18] which involves covering the surfaces of the sample (except the one that will be exposed), saturation of the specimen and chloride exposure. Then, the specimen is dry grinded to obtain a powder sample of at least six depths from the exposed surface of the specimen. Based on the determined chloride concentrations in the powder, the diffusion coefficient is calculated. The NT Build is recommended as a reference test method for chloride penetration into concrete [19]. Therefore, it is appropriate to correlate the results of chloride penetration with electrical resistivity measurement for special concrete mixtures such as binary and ternary mixtures. A similar procedure for different concrete mixture design was published, for example, in [20].

The resulting diffusion coefficient of SLWAC determined by NT Build 443 is compared to the results obtained by resistivity measurements [21] and to the results of the reference concrete mixture, which is based on an ordinary concrete made of commonly used natural aggregate and Portland cement (OPC). The reference OPC mixture has been designed and tested for mechanical and durability characteristics in previous research [22] by co-authors and the methodology remained the same for SLWAC. Therefore, the reason for choosing this type of mixture and tests is also the availability of data of reference mixture and ensuring the repetition of the same process in case of SLWAC for a successful comparison.

In the current study, two methods of measurement for obtaining the chloride-related diffusion characteristics for the studied concrete mixture are used. The diffusion parameter is one of the essential pieces of information with respect to the durability of reinforced concrete placed in an aggressive 
environment. Therefore, it is necessary to obtain the parameters of concrete sufficiently accurately and efficiently [23,24].

The comparison of the reliable but labor- and time-demanding method of chloride penetration to fast resistivity-based measurement is presented. The ratio between results of these two methods is different for every concrete mixture, so the exact correlation coefficient may be determined in order to calibrate the fast electrical resistivity measurements. This parameter shows how fundamentally the composition of the mixture, even without chemical additives, can influence the results of the electrical resistivity-based method. The calibration ratio is important with respect to the future experimental measurements of similar compositions to speed up testing without the use of the labor-intensive penetration method. The evaluated diffusion coefficient is applicable in subsequent numerical modeling related to the durability prediction.

\section{Materials, Mixture Composition and Preparation of Specimens}

The evaluated experiment is a part of the project SPS2019/126 and SP2020/120 dealing with the mechanical and durability properties of concrete made of waste red ceramic material, and the results are planned to be used for numerical modeling of the concrete. The experiments were done at the laboratories of the Koszalin University of Technology (Poland) and VSB-Technical University of Ostrava (Czech Republic).

\subsection{Materials}

The waste red ceramic aggregate (WRCFA) was used as a fine particle of the mixture (Figure 1a). This material was sourced from a local producer of airbricks in Poland and was crushed and ground at the Koszalin University of Technology. Because the laws in the European Union do not allow for construction elements to be sold for intended purposes if they did not pass quality control tests, they are usually destroyed on-site, creating massive stockpiles of clean debris. The other problem specific to some European countries (e.g., northern Poland, northern Germany, Lithuania and Latvia) is the lack of coarse aggregates; therefore, there is a need to find a suitable replacement. The original product of airbricks was crushed, ground and sorted, and the coarse aggregates were used in research [25]. The limitations and opportunities of using coarse waste ceramic aggregate for concrete production were discussed in multiple previous publications, e.g., [26-28]. In this project, the remaining fine aggregate was used; it was clean and did not contain remains of any mortar [29]. The loose density of fine red ceramic aggregate was measured as $1183.3 \mathrm{~kg} \cdot \mathrm{m}^{-3}$, bulk density as $1489.2 \mathrm{~kg} \cdot \mathrm{m}^{-3}$ and the absorptivity as $46 \%$. Commercially available artificial lightweight expanded clay aggregate (ECCA, Figure $1 \mathrm{~b}$ ) was used as the coarse aggregate. The loose density of coarse clay aggregate was determined as $318.8 \mathrm{~kg} \cdot \mathrm{m}^{-3}$, bulk density as $345.8 \mathrm{~kg} \cdot \mathrm{m}^{-3}$ and the absorptivity as $36 \%$.

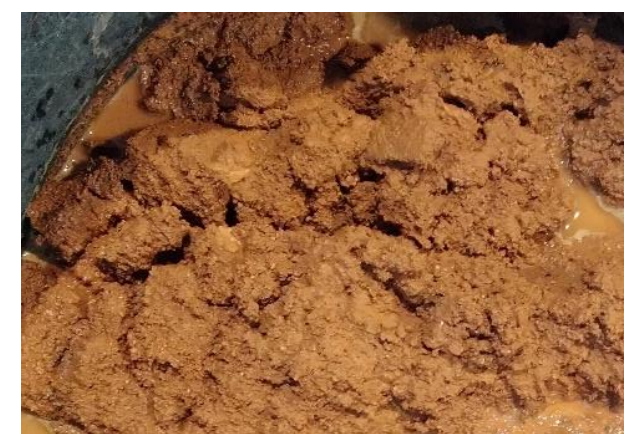

(a)

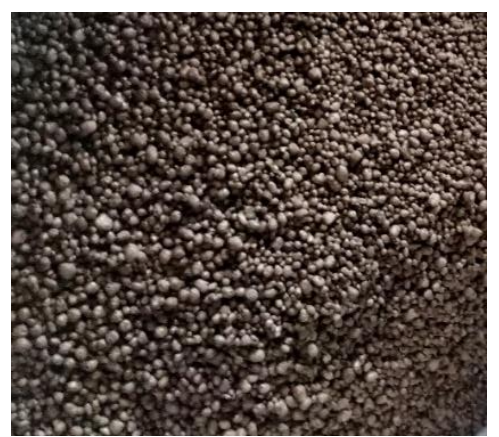

(b)

Figure 1. Waste red ceramic fine aggregate (a), expanded clay coarse aggregate (b). 


\subsection{Mixture Composition}

The requirements for the studied concrete mixture were very specific: using only pre-soaked aggregates and no additional water, specific density (to ensure the classification as a lightweight concrete), good workability of the fresh mix, and minimum voids on the surface of the sample (closed structure). These requirements were fulfilled, and the entire process of design, along with material characteristics, is described in detail in [9]. The consistency of SLWAC was measured by slump test as S2 according to [30] and the density of SLWAC after $24 \mathrm{~h}$ from casting was $1367 \mathrm{~kg} \cdot \mathrm{m}^{-3}$; therefore, the concrete can be classified as lightweight because the maximum density of lightweight concrete is given by [31] as $1800 \mathrm{~kg} \cdot \mathrm{m}^{-3}$. Mixture proportions are given in Table 1 ; the internal structure of the concrete is shown in Figure $2 b$.

Table 1. Structural lightweight waste aggregate concrete (SLWAC) and ordinary Portland cement (OPC): proportions of a cubic meter of mixture.

\begin{tabular}{ccc}
\hline Mixture & SLWAC $[9]\left[\mathbf{k g} / \mathbf{m}^{\mathbf{3}}\right]$ & OPC [22] $\left[\mathbf{k g} / \mathbf{m}^{\mathbf{3}}\right]$ \\
\hline WRCFA-dry & 379 & - \\
ECCA-dry & 247 & - \\
Cement I 42.5 & 321 & 313 \\
Absorbed water & 461 & - \\
\hline Water & - & 164 \\
Sand & - & 387 \\
River gravel & - & 1546 \\
\hline
\end{tabular}

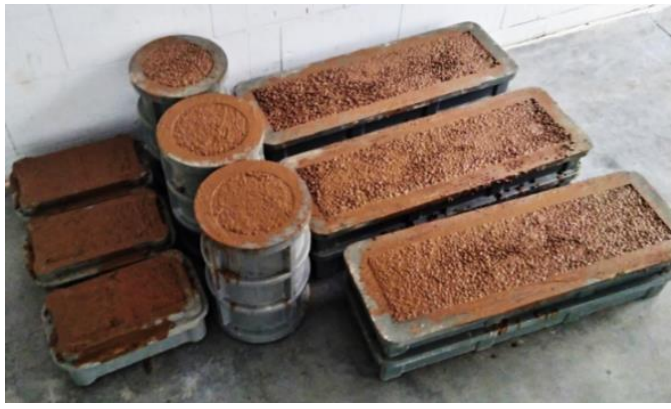

(a)

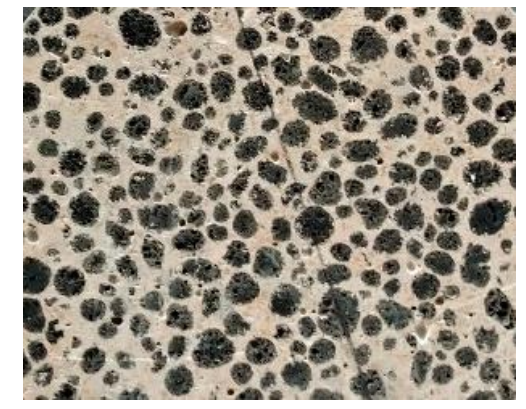

(b)

Figure 2. Set of the SLWAC specimens casted for testing of the mechanical properties (a), internal structure of the SLWAC (b).

In order to be able to evaluate the suitability of the SLWAC, the reference concrete mixture shall be selected. Therefore, ordinary concrete mixture (OPC), whose composition is similar to those commonly used for structural concrete, was taken over from the research of the co-authors [22] for the comparison of the mechanical and diffusion properties. Available OPC data can be used because the methodology of measuring resistivity and chloride profile is the same as in the case of SLWAC. The composition of the mixture is also given in Table 1. It needs to be noted that the research considers that both concretes compared were created by different approaches and technologies, e.g., SLWAC contains pre-soaked lightweight aggregate and no more mixing water was added, but OPC is made of dry aggregate with a designated amount of mixing water to cover the $\mathrm{w} / \mathrm{c}$ ratio, the process of internal hydration is not present in OPC, etc. Therefore, the materials and technological reasons for the differences in results between SLWAC and OPC concrete are not sought here, but OPC concrete serves as a certain measure for conducted research work in order to place the durability parameters of SLWAC into perspective.

As has been already mentioned above, aggregates were pre-soaked, and no additional water was added to the mixture during the mixing process [9]. Therefore, during the harnessing, concrete benefitted from the process of internal curing, which is a phenomenon based on slowly releasing 
the water from the aggregate for hydration of the cement. This process can reduce the autonomous shrinkage, which may be useful in case of avoidance of microcracks on the surface of concrete, which usually leads to a higher ingress rate into concrete [32].

Pre-soaking of the aggregate is a very easy method to procure in the field, but it is desirable to limit the usage of water as much as possible. The weight of water that was absorbed in the porous aggregate is also given in Table 1. One should notice that the amount of water is very high, the water/cement ratio for SLWAC is 1.44, and for OPC is 0.52 , which is about $65 \%$ less than in the case of SLWAC. However, it cannot be ambiguously determined to what extent the water supply from the pores of the aggregate has been exactly depleted for the internal hydration of the cement. This effect of the pre-soaking degree of lightweight aggregate on the properties of concrete was studied, e.g., in [24].

\subsection{Preparation of Specimens}

The set of specimens for mechanical testing of every mixture consisted of three large cylinders (diameter $150 \mathrm{~mm}$, height $300 \mathrm{~mm}$ ), three smaller cylinders (diameter $100 \mathrm{~mm}$, height 220 and $100 \mathrm{~mm}$ ), six cubes (dimension $150 \mathrm{~mm}$ ), and three beams $(150 \times 150 \mathrm{~mm}$, length $600 \mathrm{~mm})$, see Figure 2a.

For the resistivity measurements, three saturated cylindrical specimens with a diameter of approximately $100 \mathrm{~mm}$ and a height of $220 \mathrm{~mm}$ were used (see Figure 3a), and for the NT Build 443, three saturated cylindrical specimens with a diameter of approximately $100 \mathrm{~mm}$ and height of $100 \mathrm{~mm}$ were used (see Figure 3b).

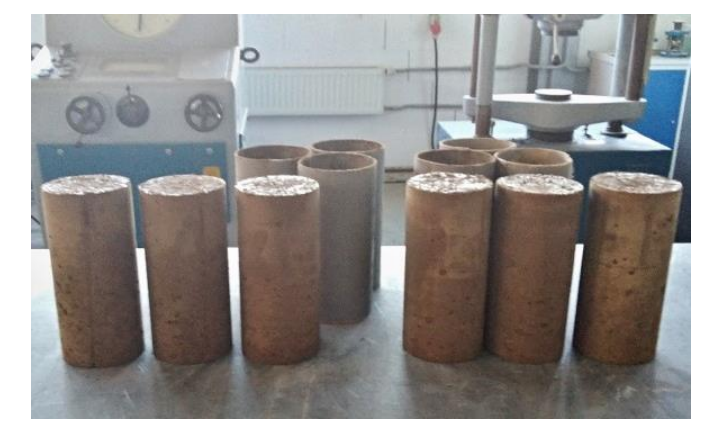

(a)

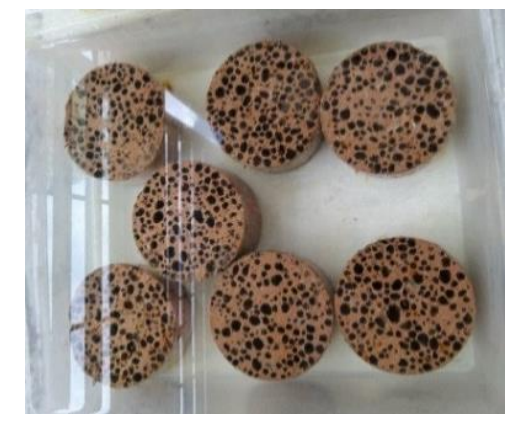

(b)

Figure 3. Specimens for measuring the resistivity (a) and for chloride profiling (b).

The specimens matured in a water tank. They were also kept in the water until the tests started to avoid the effect of carbonation and because the tests require saturated specimens. In the case of resistivity measurements, the specimens also remained in water among the individual tests in the specific time points. The SLWAC specimens for NT Build 443 were left in the water to cure for 78 days and OPC specimens for 69 days. Then, all faces of the specimens were dried for a few hours at a room temperature to a stable white-dry condition and given approximately $1 \mathrm{~mm}$ thick epoxy coating, except the one surface that should be exposed to the chloride solution as specified in the standard [17].

\section{Chloride Ingress into Concrete and Durability Test Methods}

Chloride ions can migrate through concrete as a result of a concentration gradient (diffusion), a pressure gradient causing the flow of chloride-bearing solutions through pores and capillary action. Among these transport options, diffusion is the most damaging process in case of the initiation of corrosion of the steel reinforcement of highway structures in a mild climate and marine environment. If cracks are absent, chloride diffusion depends mostly on the nature of the porosity. A low rate of diffusion is reached when the total volume fraction of porosity and constrictivity is low [33]. However, there are a lot of other parameters that influence chloride ingress (surface chloride content, the temperature at the time of casting, the age of the structure, the mechanical damage, etc.) [34]. 
Only free chloride will diffuse through the structure. If steady-state conditions have not been reached before testing, the results may be affected. The binding capacity of the specific concrete mixture is related to the used cementitious materials. Additionally, the inclusion of supplementary cementitious materials may affect the binding phenomenon; hence the exact influence is of interest to many research teams, e.g., [35,36]. In this project, there has been an attempt to use WRCFA also as a partial cementitious substitution.

\subsection{Resistivity Measurement}

Concrete resistivity is a material property that describes the ability to transport an electrical charge of chloride ions. Corrosion current density decreases as the electrical resistivity increases, which means that the corrosion rate reduces [16].

The relationship between the electrical resistivity and ion diffusivity can be expressed by the Nernst-Einstein equation (Equation (1)) [37]. This theoretical approach is used to obtain the diffusion coefficient. The procedure of measurement and calculation process are described in [17,22,38-40].

$$
D=\frac{R T}{Z^{2} F^{2}} \times \frac{t_{i}}{\gamma_{i} C_{i} \rho_{B R}}
$$

where $D$ is the diffusivity of the chloride ion $\left[\mathrm{m}^{2} \mathrm{~s}^{-1}\right] ; R$ is the universal gas constant $[\mathrm{J} / \mathrm{Kmol}] ; T$ is the absolute temperature $[\mathrm{K}] ; Z$ is the ionic valence $[-] ; F$ is the Faraday constant $[\mathrm{C} / \mathrm{mol}] ; t_{i}$ is the transfer number of chloride ion $[-] ; \gamma_{i}$ is the activity coefficient for chloride ion $[-] ; C_{i}[\mathrm{C} / \mathrm{mol}]$ is the concentration of ions $i$ in the pore water, and $\rho_{B R}$ is the bulk electrical resistivity $[\Omega \mathrm{m}]$.

The Wenner Array Probe can be used for the measurement of surface resistance. It consists of four points in a constant distance (approximately $5 \mathrm{~cm}$ ) that are applied on the surface of the specimen. The method is non-destructive, so the test can be repeated to determine the time-dependent diffusion process.

Despite the simplicity of the method, there is a risk of a relatively large variety of results because of the heterogeneity of the material and the possibility of uneven contact conditions. The electrodes are applied to the concrete surface with the help of wet sponges, so the connection may be influenced by contact pressure level and the saturation of the sponge.

\subsection{NT Build 443}

The second method for analyzing the diffusion coefficient used in this project is NT Build 443 [17]. This method is applicable to test specimens from existing structures and to new samples older than 28 maturity-days. The concrete test specimens must be free from construction faults such as cavities and visible cracks. For an adequate period (minimally 35 days), concrete specimens are immersed in aqueous $\mathrm{NaCl}$ solution $\left(165 \mathrm{~g}\right.$ per $\mathrm{dm}^{3}$ ). This test is based on natural diffusion, and it gives the non-steady-state diffusion coefficient $\left(D_{\text {nssd }}\right)$.

Since the suitable tool for grinding a thin layer of the concrete surface and subsequent collection of the powder, which is a process described in NT Build 443, is not available, the process of collecting the concrete powder needed to be slightly modified [22]. A sampling of concrete powder in layers of chloride profile was conducted by drilling. Because it was not possible to drill a thin layer of concrete, the exposure time needed to be extended to 90 days to show the differences in every layer, and also only six layers were taken instead of eight. Therefore, the SLWAC specimens were 168 days old and OPC specimens were 159 days old when the profile was analyzed.

The concentration of chloride ions in the procured concrete dust was determined by potentiometric titration [41].

After the determination of the concentration of chlorides at given depths, the measured chloride profile is approximated via Equation (2) [5], with the diffusion coefficient calculated by the method of 
least squares given by Equation (3) [17]. The procedure and the calculation process are described in detail in [40].

$$
C(x, t)=C_{0}\left\{1-\operatorname{erf}\left(\frac{x}{\sqrt{4 \cdot D_{c} \cdot t}}\right)\right\}
$$

where $C(x, t)$ [mass \%] is the chloride ion concentration at a distance of $x[\mathrm{~m}]$ from the surface of the concrete in time $t[\mathrm{~s}], \mathrm{C}_{0}$ [mass \%] is a concentration of the chloride at the surface of the concrete and erf is the error function complement; $D_{c}\left[\mathrm{~m}^{2} / \mathrm{s}\right]$ is the effective diffusion coefficient, characterizing the ability of concrete to withstand the penetration of chlorides [42].

$$
S=\sum_{n=2}^{N} \Delta C^{2}(n)=\sum_{n=2}^{N}\left(C_{\mathrm{m}}(n)-C_{\mathrm{c}}(n)\right)^{2},
$$

where $S\left[(\text { mass } \%)^{2}\right]$ is the sum of squares to be minimized, $N$ is the number of concrete layers ground off, $\Delta C(n)[$ mass $\%]$ is the difference between the measured, and the calculated chloride concentration of the $n^{\prime}$ th concrete layer, $C_{\mathrm{m}}(n)$ [mass \%] is the measured chloride concentration of the $n^{\prime}$ th concrete layer, and $C_{c}(n)$ [mass \%] is the calculated chloride concentration in the middle of the $n^{\prime}$ th concrete layer.

The obtained diffusion coefficient can be recalculated to a different time by Equation $(4)[43,44]$ :

$$
D_{\mathrm{c}}(t)=D_{\mathrm{c}, \mathrm{ref}} \cdot\left(\frac{t_{r e f}}{t}\right)^{m}
$$

where $D_{\mathrm{c}}(t)\left[\mathrm{m}^{2} \mathrm{~s}^{-1}\right]$ is the effective coefficient in the studied time, $D_{\mathrm{c}, \text { ref }}\left[\mathrm{m}^{2} \mathrm{~s}^{-1}\right]$ is the diffusion coefficient for the reference time, $t_{\text {ref }}$ [days] is the reference time, $t$ [days] is the studied time and $m$ is the coefficient of aging [-].

\section{Results and Discussion}

\subsection{Comparison of Mechanical Properties}

The compressive strength and splitting tensile strength were measured on standard cubes. The static modulus of elasticity was determined by the tests procured on standard cylinders. The tests and evaluation of results are described in detail in $[9,22]$. Measured mechanical properties are used for the first and basic comparison of the waste aggregate concrete mixture and the reference mixture. The results are shown in Figure 4 for both types of mixture.

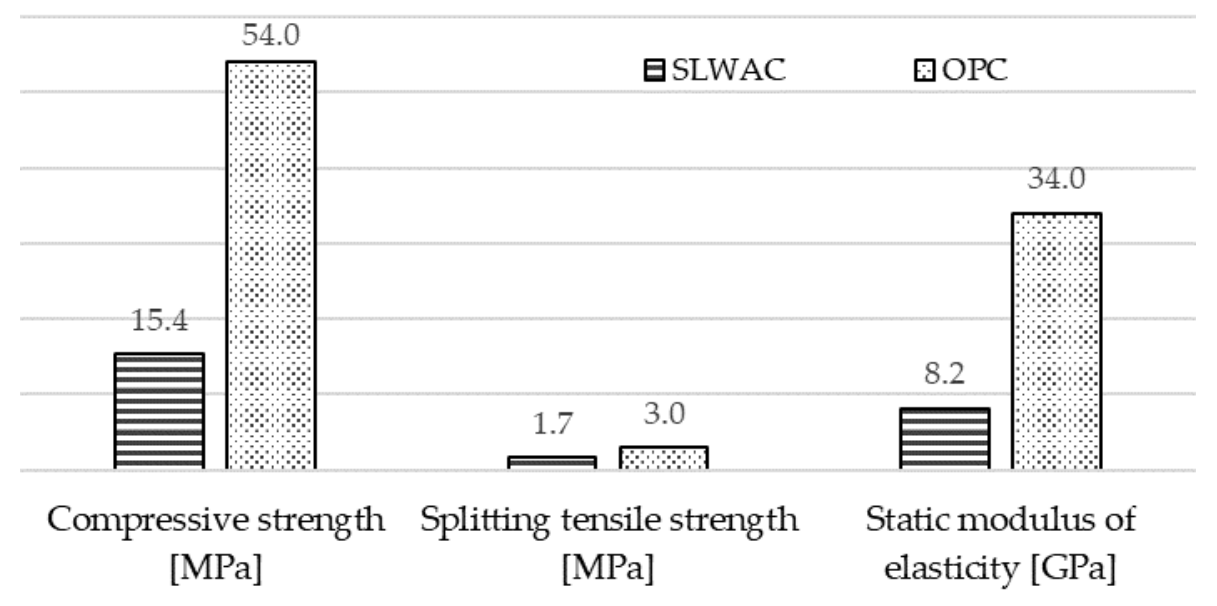

Figure 4. Mechanical properties of SLWAC [9] and OPC [22]. 
It can be seen that the properties of OPC are, in every case, higher than the SLWAC ones. The compressive strength of OPC is almost $72 \%$ higher than values measured in case of SLWAC. In terms of splitting tensile strength, the difference is not so excessive $(43 \%)$, but the static modulus of the OPC is again almost $76 \%$ higher than the static modulus of SLWAC. Thus, it is clear that the SLWAC does not exhibit the same strength properties as ordinary concrete.

\subsection{Resistivity Measurements}

The resistivity measurements were conducted continuously on cylindrical specimens at specific time intervals $(7,14,28,56,91$ and 161 days) from the casting. The measured conductivity of SLWAC and OPC are given in Figure 5. One should notice that the conductivity of the OPC is lower than that of the SLWAC, but conductivities of both concretes tend to decrease in time. The determined diffusion coefficients obtained by resistivity measurements in specific time points are given in Table 2; they also decrease in time for both concretes. Therefore, as expected, both concretes show an improvement in case of chloride ingress in time, but SLWAC is approximately two times worse than OPC. Based on the resistivity measurements in time was determined the coefficient of aging $\mathrm{m}$ by a procedure described in [45]. The aging coefficients of both mixtures are given in Table 2.

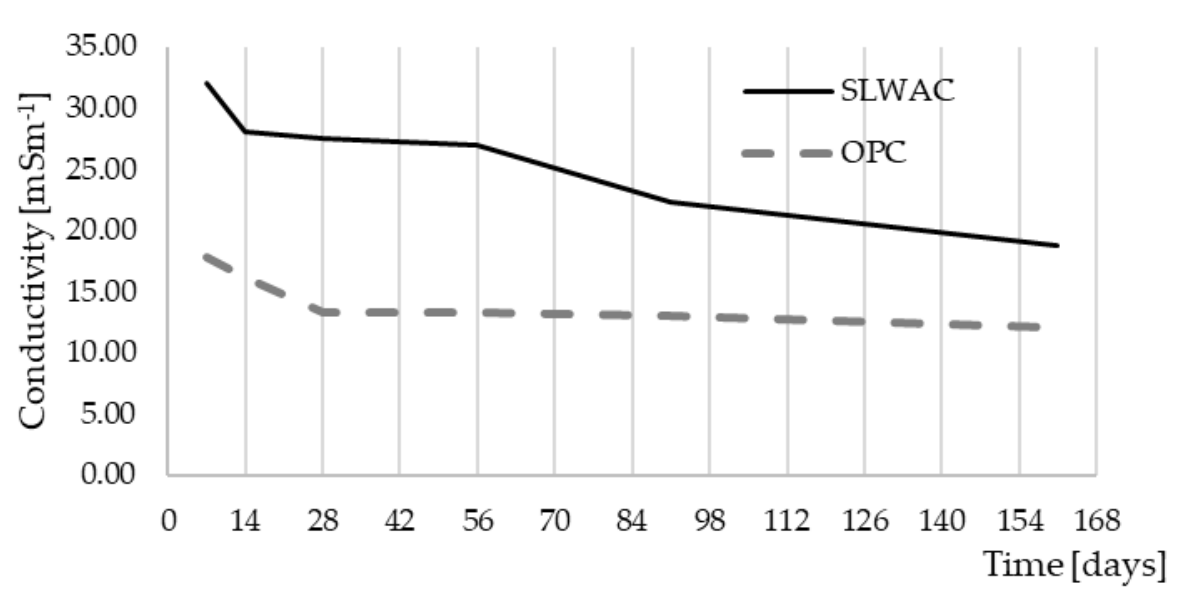

Figure 5. Measured conductivity of SLWAC [17] and OPC [22].

Table 2. Diffusion coefficient $\left[\mathrm{m}^{2} \mathrm{~s}^{-1}\right]$ calculated based on resistivity measurements $[17,22]$.

\begin{tabular}{|c|c|c|c|c|c|c|c|}
\hline \multicolumn{7}{|c|}{ Diffusion Coefficient $\left[\mathrm{m}^{2} \mathrm{~s}^{-1}\right] \times 10^{-11}$} & $m[-]$ \\
\hline Time [Days] & 7 & 14 & 28 & 56 & 91 & 161 & \\
\hline SLWAC & 2.37 & 2.07 & 2.03 & 2.00 & 1.65 & 1.39 & 0.139 \\
\hline OPC [22] & 1.31 & 1.19 & 0.987 & 0.980 & 0.961 & 0.889 & 0.126 \\
\hline
\end{tabular}

\subsection{Penetration Test (NT Build 443)}

The approximation of measured chloride concentration was done by the least square method via Equation (3). The example of the approximation is shown in Figure 6 on one of the samples; the measured values are marked by black dots and they are approximated by a green line. The diffusion coefficients calculated based on the approximation of the chloride profiles are given in Table 3. Because this test is destructive, the value of the diffusion coefficient is determined on the day the test was done; in the case of SLWAC it was 168 days after casting and in the case of OPC it was 159 days after casting. Based on the results, the diffusion coefficient of SLWAC is approximately $70 \%$ higher than the diffusion coefficient of OPC. 


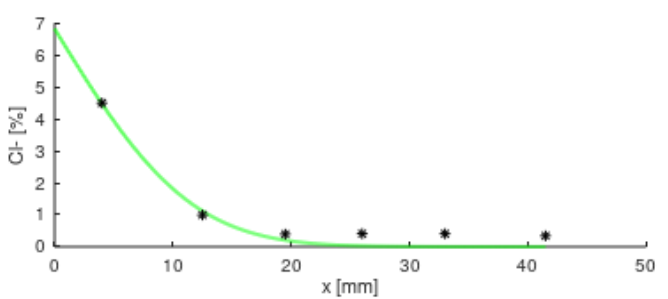

Figure 6. Measured chloride profile approximated by a diffusion curve.

Table 3. Diffusion coefficients calculated based on the data measured by NT Build 443.

\begin{tabular}{ccc}
\hline Mixture & SLWAC & OPC [22] \\
\hline Time & $\mathrm{t}=168$ days & $\mathrm{t}=159$ days \\
\hline Diffusion coefficient $D_{\mathrm{c}, \mathrm{t}}\left[\mathrm{m}^{2} \mathrm{~s}^{-1}\right]$ & $3.48 \times 10^{-11}$ & $1.05 \times 10^{-11,}$ \\
\hline
\end{tabular}

\subsection{Correlation Coefficient}

One should note that the diffusion coefficient of SLWAC measured by the procedure of NT Build 443 is about $60 \%$ higher $\left(3.48 \times 10^{-11} \mathrm{~m}^{2} \mathrm{~s}^{-1}\right.$ in 168 days $)$ in comparison to the diffusion coefficient obtained by resistivity measurements $\left(1.39 \times 10^{-11} \mathrm{~m}^{2} \mathrm{~s}^{-1}\right.$ in 161 days), but in case of OPC, the results of the diffusion coefficient measured by the two methods are closer to each other: the difference is approximately $15 \%$ (see Figure 7).

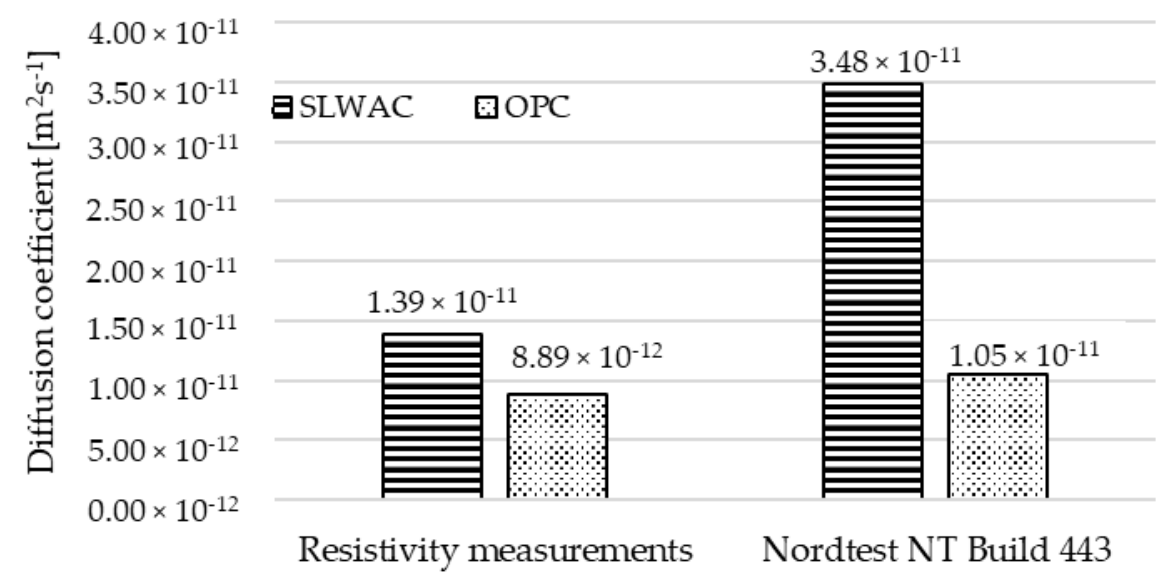

Figure 7. Diffusion coefficients of SLWAC and OPC measured by resistivity and NT Build 443.

The coefficient of aging (see Table 2) was used to recalculate the diffusion coefficient obtained by NT Build 443 to the reference time of 28 days after casting via Equation (4). After that, the correlation coefficient was calculated as the ratio between the diffusion coefficient from the resistivity test measured in 28 days and from NT Build 443 test. The value of the ratio of SLWAC is almost two times higher than the ratio of OPC. The calibration ratio between the two investigated tests is presented in the Table 4.

Table 4. Diffusion coefficients of mixtures at 28 days and correlation coefficients.

\begin{tabular}{ccc}
\hline Mixture & SLWAC & OPC \\
\hline $\boldsymbol{D}_{\mathrm{c}, \text { res,28 }}\left[\mathrm{m}^{\mathbf{2}} \mathbf{~ s}^{\mathbf{- 1}}\right]$ in 28 days-resistivity & $2.03 \times 10^{-11}$ & $0.987 \times 10^{-11}$ \\
$\boldsymbol{D}_{\mathbf{c}, \mathbf{N T} 443,28}\left[\mathbf{m}^{\mathbf{2}} \mathbf{s}^{-1}\right]$ in 28 days-NT Build 443 & $4.46 \times 10^{-11}$ & $1.31 \times 10^{-11}$ \\
Ratio $\boldsymbol{D}_{\mathbf{c}, \mathbf{N T} 443,28} / \boldsymbol{D}_{\mathbf{c}, \mathbf{r e s}, \mathbf{2 8}}$ & 2.20 & 1.32 \\
\hline
\end{tabular}




\section{Conclusions}

The article deals with the evaluation of concrete material parameters related to durability. Two approaches, chloride profiling according to the immersion test NT Build 443, and electrical resistivity measurement, are utilized. NT Build 443 lasts a relatively long time, requires intensive labor and is not able to effectively capture the effect of aging of the concrete, and the resistivity measurements are non-destructive tests and thus can be repeated and also provide the possibility to obtain a time-dependent value of the diffusion coefficient. However, results of electrical resistivity require calibration for other concrete mixtures than OPC.

An important finding is that that the properties of the studied mixture from waste red ceramic aggregate are approximately two times worse when compared to the ordinary concrete mixture. Therefore, in terms of durability, the concrete reports lower tolerance to aggressive agents and it is not suitable for aggressive environments.

The results also show the unevenness in terms of resistivity measurements and chloride profiling of SLWAC. The diffusion coefficient of SLWAC measured by NT Build 443 is 2.2 times higher than value measured by resistivity measurements. In case of OPC, the correlation ratio of diffusion coefficients measured by the two methods is significantly lower (1.3 times). Therefore, it was confirmed that resistivity-based method needs to be adjusted in order to match the result of NT Build 443 to determine the diffusion coefficient sufficiently for further usage with respect to the utilization of faster electrical resistivity measurements in the case of SLWAC concrete mixture.

Measured values of diffusion characteristics can be used as input parameters for modeling of degradation processes and estimation of durability of structures made of SLWAC (or OPC respectively). However, it needs to be noted that the methods of measurement and calculation of diffusion properties deserve attention and possibly even modification related to the waste aggregate concrete, since usually it is used for ordinary concrete mixtures, as was also indicated by the computed correlation factor between electrical resistivity and penetration test-based results.

The values of the mechanical properties of SLWAC are also lower than in the case of OPC; for example, compressive strength, which is one of the most important parameters, is almost four times lower. Even though the mechanical and durability parameters are not very good, the concrete mixture can still be used, e.g., as prefabricated bricks for family houses or as a building material for less loaded buildings in less aggressive environments or non-aggressive environments.

Based on the composition of SLWAC, one should note that the amount of water trapped in the pores of aggregate is very high (about 65\% more than in OPC). The combination of dry aggregate and partially pre-soaked aggregate to ensure internal curing, and a small amount of mixing water to provide good workability, could be a better solution to provide better mechanical and durability characteristics. It would be desirable to test other compositions similar to the studied one, but with less water, to determine the changes in the mechanical and durability parameters.

Author Contributions: Conceptualization, M.H. and P.L.; methodology, M.H., and T.D.L.; formal analysis, M.H. and P.L.; investigation, M.H. and J.K.; resources, M.H., P.K. and J.K.; data curation, P.L.; writing一original draft preparation, M.H.; writing-review and editing, P.L.; visualization, P.L.; supervision, P.L., P.K. and J.K.; project administration, M.H.; funding acquisition, M.H., P.K. and J.K. All authors have read and agreed to the published version of the manuscript.

Funding: The research was funded by the Ministry of Education, Youth and Sports of the Czech Republic through VSB-Technical University of Ostrava (SGS SP2020/120).

Acknowledgments: The support of the grant program "Support for Science and Research in the Moravia-Silesia Region 2018" (RRC/10/2018), financed from the budget of the Moravian-Silesian Region, is highly acknowledged.

Conflicts of Interest: The authors declare no conflict of interest. 


\section{References}

1. Assi, L.; Carter, K.; Deaver, E.E.; Anay, R.; Ziehl, P. Sustainable concrete: Building a greener future. J. Clean. Prod. 2018, 198, 1641-1651. [CrossRef]

2. Latawiec, R.; Woyciechowski, P.; Kowalski, K.J. Sustainable Concrete Performance-CO2-Emission. Environments 2018, 5, 27. [CrossRef]

3. Ghosh, P.; Quang, T.; Tuan, L. Compressive Strength and Surface Electrical Resistivity of HPC Mixtures. Int. J. Eng. Sci. Manag. 2014, 4, 1-10.

4. Tran, Q.; Ghosh, P. Influence of pumice on mechanical properties and durability of high performance concrete. Constr. Build. Mater. 2020, 249, 118741. [CrossRef]

5. Lin, G.; Liu, Y.; Xiang, Z.-H. Numerical modeling for predicting service life of reinforced concrete structures exposed to chloride environments. Cem. Concr. Compos. 2010, 32, 571-579. [CrossRef]

6. Folic, R.; Zenunovic, D. Durability design of concrete structures, Part 2: Modelling and structural assessment. Facta Univ. Ser. Arch. Civ. Eng. 2010, 8, 45-66. [CrossRef]

7. Konecny, P.; Lehner, P.; Brozovsky, J.; Krejsa, M. Multilevel Durability Analysis of Concrete Bridge Deck Exposed to Chlorides. Fifteenth Int. Conf. Civ. Struct. Environ. Eng. 2015, 108. [CrossRef]

8. Horn, L. Targeted/Emerging Therapies for Metastatic Non-Small Cell Lung Cancer. J. Natl. Compr. Cancer Netw. 2015, 13, 676-678. [CrossRef]

9. Hornakova, M.; Katzer, J.; Kobaka, J.; Konecny, P. Lightweight SFRC Benefitting from a Pre-Soaking and Internal Curing Process. Materials 2019, 12, 4152. [CrossRef]

10. Mehta, P.K.; Monteiro, P.J. Concrete Structures, Properties and Materials; McGraw Hill Education: New York, NY, USA, 2017.

11. Lencioni, J.W.; De Lima, M.G.; Büyüköztürk, O.; Taşdemir, M.A. A Study of the Parameters that Affect the Measurements of Superficial Electrical Resistivity of Concrete. In RILEM Bookseries; Springer: Dordrecht, The Netherlands, 2011; Volume 6. [CrossRef]

12. Hooton, R.D.; Thomas, M.D.A.; STANDISH, K. Prediction of Chloride Penetration in Concrete; Federal Highway Administration: Washington, DC, USA, 2001; p. 405.

13. Tikalsky, P.J.; Scheetz, B.E.; Tepke, D.G. Statewide high performance concrete initiative, task 6, Final report. In Penndot Research; Pennsylvania State University: State College, PA, USA, 2007.

14. Ramezanianpour, A.A.; Pilvar, A.; Mahdikhani, M.; Moodi, F. Practical evaluation of relationship between concrete resistivity, water penetration, rapid chloride penetration and compressive strength. Constr. Build. Mater. 2011, 25, 2472-2479. [CrossRef]

15. Ghosh, P.; Tran, Q. Correlation Between Bulk and Surface Resistivity of Concrete. Int. J. Concr. Struct. Mater. 2014, 9, 119-132. [CrossRef]

16. Lübeck, A.; Gastaldini, A.; Barin, D.; Siqueira, H. Compressive strength and electrical properties of concrete with white Portland cement and blast-furnace slag. Cem. Concr. Compos. 2012, 34, 392-399. [CrossRef]

17. Nordtest. Nordtest NT BUILD 443, Concrete, Hardened: Accelerated Chloride Penetration; Nordtest: Espoo, Finland, 1995.

18. Sorensen, H.E. Nordtest Project 1154-94, Determination of Chloride Penetration Parameters for Concrete; AEC Laboratory Report No. 94-019; AEC Consulting Engineers Ltd.: Vedbek, Denmark, 1995.

19. Luping, T.; Sørensen, H. Evaluation of the Rapid Test Methods for Measuring the Chloride Diffusion Coefficients of Concrete; NORDTEST Project No. 1388-98; Swedish National Testing and Research Institute Building Technology: Borås, Sweden, 1998.

20. Gao, P.; Wei, J.; Zhang, T.; Hu, J.; Yu, Q. Modification of chloride diffusion coefficient of concrete based on the electrical conductivity of pore solution. Constr. Build. Mater. 2017, 145, 361-366. [CrossRef]

21. Hornakova, M.; Konecny, P.; Lehner, P.; Katzer, J. Durability of structural lightweight waste aggregate concrete-Electrical resistivity. In MATEC Web of Conferences; EDP Sciences: Ulis, France, 2020. [CrossRef]

22. Lehner, P.; Konečný, P.; Ponikiewski, T. Comparison of Material Properties of SCC Concrete with Steel Fibres Related to Ingress of Chlorides. Crystals 2020, 10, 220. [CrossRef]

23. Nilsson, L.O.; Poulsen, E.; Sandberg, P.; Sorensen, H.E. Klinghoffer, O. Chloride Penetration into Concrete. State of the Art. Transport Processes, Corrosion Initiation and Prediction Models; Danish Road Directorate: Copenhagen, Denmark, 1996; ISBN 8774917366. 
24. Tang, C.-W. Effect of presoaking degree of lightweight aggregate on the properties of lightweight aggregate concrete. Comput. Concr. 2017, 19, 69-78. [CrossRef]

25. Katzer, J.; Kobaka, J. Harnessing Waste Fine Aggregate for Sustainable Production of Concrete Precast Elements. Rocz. Ochr. Sr. 2010, 12, 33-45.

26. Suzuki, M.; Meddah, M.S.; Sato, R. Use of porous ceramic waste aggregates for internal curing of high-performance concrete. Cem. Concr. Res. 2009, 39, 373-381. [CrossRef]

27. Cichocki, K.; Domski, J.; Katzer, J.; Ruchwa, M. Mechanical Properties and Numerical Approach to Fibre Reinforced Wca Concrete Slabs. In Brittle Matrix Composites 11, Proceedings of the 11th International Symposium on Brittle Matrix Composites (BMC 2015), Warsaw, Poland, 28-30 September 2015; Institute of Fundamental Technological Research, Polish Academy of Sciences: Warsaw, Poland.

28. Rahhal, V.F.; Trezza, M.A.; Tironi, A.; Castellano, C.C.; Pavlíková, M.; Pokorný, J.; Irassar, E.F.; Jankovský, O.; Pavlík, Z. Complex Characterization and Behavior of Waste Fired Brick Powder-Portland Cement System. Materials 2019, 12, 1650. [CrossRef]

29. Katzer, J.; Kuźmińska, E. Optimal Composition of Blended Waste Ceramic Aggregate. Sustain. Constr. Mater. Technol. 2016, 145. [CrossRef]

30. EN 12350-2. Testing Fresh Concrete, Part 2: SLUMP Test; British Standard Institution: London, UK, 2009.

31. EN 206-1. Performance-Based Specifications and Control of Concrete Durability. Concrete. Part 1, Specification, Performance, Production and Conformity; British Standard Institution: London, UK, 2006.

32. Liu, J.; Shi, C.; Ma, X.; Khayat, K.H.; Zhang, J.; Wang, D. An overview on the effect of internal curing on shrinkage of high performance cement-based materials. Constr. Build. Mater. 2017, 146, 702-712. [CrossRef]

33. Dyer, T. Concrete Durability; CRC Press: London, UK, 2014; ISBN 978-0415564755.

34. Poulsen, E.; Mejlbro, L. Diffusion of Chloride in Concrete: Theory and Application; Taylor \& Francis: London, UK, 2010.

35. Thomas, M.; Hooton, R.; Scott, A.; Zibara, H. The effect of supplementary cementitious materials on chloride binding in hardened cement paste. Cem. Concr. Res. 2012, 42, 1-7. [CrossRef]

36. Saillio, M.; Baroghel-Bouny, V.; Barberon, F. Chloride binding in sound and carbonated cementitious materials with various types of binder. Constr. Build. Mater. 2014, 68, 82-91. [CrossRef]

37. Lu, X. Application of the Nernst-Einstein equation to concrete. Cem. Concr. Res. 1997, 27, 293-302. [CrossRef]

38. Konecny, P.; Lehner, P.; Ponikiewski, T.; Miera, P. Comparison of Chloride Diffusion Coefficient Evaluation Based on Electrochemical Methods. Procedia Eng. 2017, 190, 193-198. [CrossRef]

39. Ghosh, P. Computation of Diffusion Coefficients and Prediction of Corrosion Initiation in Concrete Structures. Ph.D. Thesis, The University of Utah, Salt Lake City, UT, USA, 2011.

40. Lehner, P.; Turicová, M.; Konecny, P. Comparison of selected methods for measurement of the concrete electrical resistance to chloride penetration. ARPN J. Eng. Appl. Sci. 2017, 12, 937-944.

41. ČSN EN 14629. Products and Systems for the Protection and Repair of Concrete Structures. Test Methods. Determination of Chloride Content in Hardened Concrete; ČNI: Prague, Czech Republic, 2008.

42. Collepardi, M.; Marcialis, A.; Turriziani, R. Penetration of Chloride Ions into Cement Pastes and Concretes. J. Am. Ceram. Soc. 1972, 55, 534-535. [CrossRef]

43. Boddy, A.; Bentz, E.; Thomas, M.; Hooton, R. An overview and sensitivity study of a multimechanistic chloride transport model. Cem. Concr. Res. 1999, 29, 827-837. [CrossRef]

44. Luping, T.; Nilsson, L.O. Rapid Determination of the Chloride Diffusivity in Concrete by Applying an Electrical Field. ACI Mater. J. 1992, 89, 40-53.

45. Konečný, P.; Lehner, P.; Ghosh, P.; Morávková, Z.; Tran, Q. Comparison of procedures for the evaluation of time dependent concrete diffusion coefficient model. Constr. Build. Mater. 2020, 258, 119535. [CrossRef]

Publisher's Note: MDPI stays neutral with regard to jurisdictional claims in published maps and institutional affiliations. 